\title{
A Forward-Looking Justification of Territorial Rights
}

[ACCEPTED PRE-PROOF VERSION, Angell, Kim (2017): “A Forward-Looking

Justification of Territorial Rights", Political Studies, Vol. 65, No. 1: 231-247.]

Abstract: According to a prominent forward-looking justification of territorial (jurisdictional) rights, people may establish such rights over a piece of land if they develop economic and/or religious-cultural life plans the satisfaction of which requires controlling it. This argument suffers from a gap problem. The relevant life plans can be satisfied without granting their holders jurisdictional authority. Having lesser entitlements, such as occupancy rights, is sufficient. In this paper I offer a new forward-looking justification which plugs this justificatory gap. It follows the general framework of life plans-arguments, but develops a new category of plans: a person's political plan to exercise her democratic autonomy as a citizen of the state under which she (or her group) has lived, or is living.

Keywords: life plans; territorial rights; jurisdiction; occupancy; basic liberties 


\section{Introduction}

The justification of territorial rights has received much attention recently. Much of the debate has thus far been inspired by John Locke's well-known labour theory of appropriation (1988). On one prominent interpretation, which is backward-looking in character, collective agents may come to deserve territorial rights over lands they have laboured to improve (Nine 2008a, Miller 2007). But the labour theory has also inspired a forward-looking justification of such rights. This justification starts with the idea that people may labour on external objects by incorporating them into their economic and religious-cultural life plans. When this has happened, respect for people's interest in authoring their own lives requires non-interference with established plans (Waldron 1992, pp. 16-20). Insofar as people develop plans that revolve around controlling particular lands, they need rights over those lands in order to sustain their ways of life, presently and for the future (cf. e.g. Miller 2012; Stilz 2013 and 2011; Meisels 2009; Gans 2008; Waldron 2004 and 1992).

Such forward-looking justifications confront the following difficulty. In principle, people do not need territorial (jurisdictional) rights ${ }^{1}$ to satisfy their economic and/or religiouscultural life plans (Miller 2012, p. 263). In other words, the justification based upon such plans - which I shall call non-political life plans (NLPs) - faces a gap problem: the normative concerns it identifies can be satisfied without establishing the rights-distribution the NLPargument sets out to justify. This justificatory gap has been sought plugged in various ways. However, because those attempts, as we shall see, rely upon normative considerations external to the NLP-argument, they are, at best, ad hoc-solutions.

My main contribution in this paper is to demonstrate that a purely life plans-based theory can carry us all the way. I offer a justification which follows the general structure of life plans-arguments, but develops a new category of plans. What I call a political life plan (PLP) refers to: a person's plan to exercise her democratic autonomy as a citizen of the state 
under which she (or her group) has lived, or is living. I shall argue that PLPs, if and when they exist, cannot be satisfied without granting (collective) jurisdictional rights to their holders. If this is correct my account solves the gap problem. Moreover, it does so without relying upon further normative concerns than those already appealed to by any life plansapproach.

The PLP-account provides an independent justification of jurisdictional rights. But it need not stand alone. It is compatible with existing NLP-approaches, and can be incorporated as an improvement which enables them to close the justificatory gap. My account can also benefit from such a combined approach, where the PLP-category complements NLPcategories, instead of replacing them. I address this towards the end.

Clearly, developing a remedy for the gap problem does not amount to a full-blown defence of the PLP-account (nor of a combined account). My aim is not to provide such a defence. As I present it here, the PLP-account is offered as an improvement over existing NLP-accounts, as viewed from within the general framework accepted by all life plansapproaches. Issues that must ultimately be addressed by any argument that appeals to the moral significance of life plans are therefore put aside here. ${ }^{2}$

The paper proceeds as follows. I start by outlining the NLP-justification and its gap problem. I briefly consider three recent ad hoc-attempts to close the gap, and point to some weaknesses with them. I then turn to develop my non-ad hoc solution to the gap problem, which introduces the novel PLP-category. I give an account of what it means to have a PLP, and why the existence of PLPs might plug the gap. I then outline a foundation for the claim made by life plans-approaches generally - that people have a weighty interest in plansatisfaction. I also explicate how the PLP-account can justify collective rights based upon such individual interests. I then address some issues pertaining to the application of my PLPjustification, before I conclude. 


\section{The NLP-Argument}

The NLP-argument is found in several recent theories of jurisdictional rights, including the prominent theories of David Miller (2012) and Anna Stilz (2013; 2011). The account given by Stilz is especially detailed, so I shall focus mostly on her work when I now reconstruct the argument.

As I understand it for present purposes, the NLP-argument has four main components. The first is the claim that people have a morally weighty interest in sustaining their existing projects and pursuits (Stilz 2013, pp. 334-9). For now, I shall provisionally assume this first claim, and regard people's interest in realising their life plans as generally weighty. When I later discuss how that moral weight can be accounted for, I specify how principles of justice constrain the weight of certain life plans. One thing we can note right away, however, is that a plan's weight tends to vary according to its place in a plan-hierarchy, all else equal. As Stilz (ibid, pp. 336-7) puts it, our most weighty plans are comprehensive. They 'organize many choices, and are fundamental to our sense of our lives as our own'. Because '[o]ur goals are hierarchically organized' the comprehensive plans give direction to our 'everyday choices'; the latter are made 'in part because they contribute to the achievement of more abstract, pervasive aims'. As an example of comprehensive plans, Stilz mentions careers, friendships and religious and cultural activities. Examples of non-comprehensive, or peripheral, plans are '[w] hat color to paint my house and which supermarket to shop in'. To the extent that 'our flourishing is not threatened by interference with [such] peripheral plans', our interest in sustaining them takes on correspondingly less moral weight.

The NLP-justification's second main feature is its claim about which categories of life plans people typically establish. Miller (2012, p. 258-60) and Stilz (2013, p. 338) both operate with a distinction between economic (or 'material') plans and those that are religious-cultural 
(or 'symbolic'). As Stilz (ibid.) puts it, 'economic practices' refer to activities which generate income and subsistence for their practitioners, ranging from 'hunting wild buffalo' to 'modern [...] white collar professional jobs'. Plans revolving around 'membership in religious, social, and cultural organizations' include partaking in activities in 'churches, mosques, schools, meetinghouses, and so on' ${ }^{3}$

The third feature is the claim that NLPs are typically connected to (particular) places. Stilz illustrates the claim as follows:

Suppose you run a dairy farm, an economic practice that structures much of your life. You could not continue to pursue this practice if you were moved, say, to the Brazilian rainforest or the American Southwest. Our religious, cultural, or recreational activities also often have territorial components: think of how sled-dog racing belongs in the Arctic and surfing in coastal areas, or of how religions incorporate places or natural formations into their rituals of observance. (2013, pp. 335-6).

With a helpful term, Stilz suggests that we 'call these situated goals, relationships, and projects our located life plans' (ibid, p. 336). (In Miller's preferred formulation, 'material' and 'symbolic' value become 'embodied' in a piece of land in the sense that controlling that land has become necessary for sustaining the ways of life which its occupants find valuable [2012, p. 263].)

It is important to emphasize that satisfaction of a located NLP typically requires giving its holder control over particular located objects (Stilz 2013, pp. 334-340; Miller 2012, p. 260-1). A person's NLP is interfered with whenever those particular objects are made unavailable to her, regardless of whether she gets access to generically similar substitute objects. Stilz's dairy farm example is too underspecified to get this additional point across. 
Imagine that the dairy farmer plans to pursue dairy farming as such, rather than to pursue it at a particular farm. She would then have, we might say, a (moderately) generic NLP. ${ }^{4}$ Because dairy farming cannot at all be done in the Brazilian rainforest, forcing the farmer to resettle there would interfere with her NLP. Shuffling her around to a different dairy farm somewhere else, however, would not.

How can the NLP-theorist be certain that a person's plan indeed revolves around the particular objects which the NLP-argument attempts to bring under that person's control? Why not suppose instead that NLPs are (more or less) generic? When faced with this "generic, not particular"-objection, the NLP-theorist might appeal to human psychology and claim that people typically develop non-generic NLPs. As Waldron puts it, when a particular object has been at the centre of our life plans over a significant amount of time, we tend to develop 'sentimental attachment' to it. The object has become a non-fungible good; it cannot be replaced without loss. To develop sentimental attachment to particular places, he claims, is very common: 'a settlement that exists for several generations will almost certainly become a focus for the sentiments and affections of those who live there' (2004, p. 259-261). Stilz follows suit. She discusses a 'suburban loner' who 'lives in a cookie-cutter suburb, telecommutes, and needs only fiber-optic cable and an Internet connection to feel at home'. This person, she writes, has 'very generic located life plans', and it might not matter to him which one among 'a plurality of modern, suburban, English-speaking social settings [...] he inhabits'. However, 'for modern people generally', she maintains, 'the stability of located life plans' matters (2013, p. 340).

Probability-claims like these might well be correct, and I think they are. In the end, however, the NLP-theorist must reply to the "generic, not particular"-objection as follows: “Although it seems plausible (to me) to expect that people's NLPs will typically be connected to particular objects/places, to be certain in any specific case, we must ask them". (As we 
shall see below, this objection can be pressed against the PLP-justification too. The response must be the same: we must simply ask the candidate plan-holders.)

The fourth feature is that located NLPs typically revolve around participation in shared activities. The interest in pursuing one's NLPs is thus 'an interest in joint activity with others' (Stilz 2013, p. 336). Borrowing a term from Joseph Raz, Stilz says that a person's located life plans depend upon 'social forms' (ibid.). That is, 'forms of behavior which are in fact widely practiced in his society' (Raz 1986, p. 308). When persons develop and pursue NLPs they do so in circumstances where existing social practices influence the available pursuits. As Stilz puts it, '[f]or a person to undertake a religious, recreational, educational, or work activity means being able to participate in social practices that constitute these options' (2013, p. 336).

We can sum up the NLP-justification with the following quote from Stilz: 'the people who live on a territory have important plan-based interests in continuing to occupy that place, and in using it for the located social, cultural, and economic practices that they value' (2013, p. 339).

As I said above, I provisionally assume the moral weight of plan-based interests. This includes the claim that such interests are weighty enough to justify imposing duties on third parties not to interfere. That is, those interests ground rights over the external objects people need to carry out their plans. ${ }^{5}$

\section{A Gap in the NLP-Argument}

Even though you can claim rights to occupy a certain territory in order to carry on with your located pursuits, this implies nothing about who has jurisdictional authority over that territory. This is conceded by proponents of the NLP-justification. David Miller, for one, admits that having lesser entitlements than jurisdictional rights is in principle sufficient for 
sustaining one's economic and religious-cultural ways of life. As he writes, people must be granted territorial occupancy to realise their plans, but 'this does not entail having a state with [...] rights of jurisdiction' (2012, p. 263; see also p. 258).

To appreciate Miller's claim, consider this. As seen, the NLP-argument claims that people have a morally weighty interest in NLP-satisfaction. What is at stake is people's ability to sustain their economic and/or religious-cultural activities on the relevant territory without interference. However, if that is what matters, having jurisdictional rights is superfluous. People who have established located NLPs on the territory controlled by an encompassing state may sustain those NLPs as long as the state refrains from interfering with them. The state could institutionalise such non-interference by employing various "self-binding" measures which function as 'explicit restraints on the legislative power of parliamentary majorities' (Lijphart 1999, p. 216). Prime examples of such institutional arrangements are rigid constitutions (changeable only with supermajorities) and judicial review; others include veto rights, bicameralism, and even federalist power-sharing. ${ }^{6}$

With such arrangements in place - ensuring, say, rights of private property, religious freedom, and cultural protection - people can be expected to stably sustain their economic and religious-cultural ways of life on the encompassing state's territory without wielding jurisdictional authority. The NLP-justification therefore incurs a gap problem. People's interest in sustaining their shared NLPs can be satisfied without their having the jurisdictional rights the NLP-argument aims to justify. ${ }^{7}$

Let us now consider some recent attempts to plug this gap.

\section{Plugging the Gap: Three Attempts}

A version of the NLP-argument was put to use by Jeremy Waldron in his well-known justification of jurisdictional rights for colonist-descendants, in Australia, New Zealand, and 
North America (1992, pp.16-20). Commenting specifically upon Waldron's colonisationcases, Tamar Meisels (2009, p. 79) has argued that we can solve the NLP-argument's gap problem by adding a further normative claim. Because any individual is entitled to equal democratic rights in the state on whose territory she rightfully resides, once the colonistdescendants are granted (NLP-based) occupancy rights they will, due to their (typically overwhelming) numbers, indirectly receive jurisdictional authority. Unless we weigh their votes in a (grossly) disproportional way - which, Meisels writes, 'of course we would not' this traverses the justificatory gap between occupancy and jurisdiction. If Meisels's argument is correct, the NLP-argument's ability to ground jurisdictional rights seems restored, at least in the relevant colonisation-cases. Colonist-descendants may rightfully sustain (indirect) jurisdictional authority over colonised territories.

Meisels's argument might succeed in placing jurisdictional rights in the hands of the colonist-descendants rather than the indigenous group. However, her argument is ultimately unsuccessful because it does not give those jurisdictional rights the appropriate amount of stringency. To see this, consider:

Benevolent Annexation: A benevolent annexor, Big, declares to the citizens of Small, a well-functioning democracy: 'From now on, you are equal citizens of the new democratic state Bigger, in which we, the members of Big, constitute a parliamentary majority. But we guarantee you (through constitutional protection, etc.) that none of your existing economic and religious-cultural plans will be interfered with'.

Unilateral annexations like Big's seem intuitively wrong (Stilz 2011, p. 590). But Meisels's argument provides no resources to forbid them. After all, benevolent annexations violate neither the inhabitants' interest in sustaining their NLPs nor their interest in 
democratic participation. As a result, the jurisdictional authority that Meisels's argument is capable of justifying for the colonist-descendants is counter-intuitively flimsy: it depends upon the whims and wills of other (more populous) states, and survives only as long as such foreign powers abstain from benevolent annexation.

This flimsiness applies to non-colonisation cases as well. If jurisdictional rights are sought grounded solely upon occupancy rights and democratic equality, benevolent annexation of first-comer states cannot be forbidden either. The Icelanders, for example, could be faultlessly annexed by whoever is benevolent, populous enough, and up for the task. Moreover, it would follow from Meisels's argument that the historic usurpation of indigenous peoples' jurisdictional authority by European powers (e.g. in Australia and the Americas) was not unjust per se, but only in its means. That implication alone should be enough to reject any theory which is incapable of justifying what I will call annexation-resistant jurisdictional rights.

In what follows, I assume that our aim is to justify annexation-resistant rights. I do not suggest that such rights are stringent enough to resist any sort of annexation (e.g. to avert large-scale human rights abuses). But I shall take it that we want to rule out annexation of sufficiently well-functioning democracies. ${ }^{8}$ Upon closer reflection, then, having clarified our justificatory aim, we realize that the gap problem persists even when the NLP-justification receives ad hoc-support from Meisels's democratic equality-argument. The relevant normative concerns can be satisfied without conferring annexation-resistant jurisdictional rights. So, to solve the gap problem, we must find a way to forbid benevolent annexation. Can the other plugging-attempts achieve this?

David Miller offers an argument with a republican flavour. After conceding that the interest in NLP-satisfaction merely grounds occupancy rights for a group, he claims that the actual long-term satisfaction of NLPs will always be insecure unless the group also wields 
jurisdictional rights (2012, p. 263). Whenever a group (such as Small) is in numerical minority, the occupancy rights needed for NLP-satisfaction can always be cancelled by (sufficiently large) democratic majorities. On what I regard as the most plausible reconstruction of Miller's argument, it claims (roughly) that having to live under such insecurity is morally unacceptable; that it should be reduced as much as possible; that granting the group legal jurisdictional rights in international law will reduce the insecurity as much as possible; and that the group should therefore receive such rights (Angell 2013, pp. 185-187). If plausible, Miller's insecurity argument would forbid benevolent annexation. However, I think there is reason to doubt that it will work. In Miller's favoured reform of international law, the group's NLP-satisfaction is sought secured through granting them jurisdictional rights. That includes secessionist-rights. But if it does, then an alternative reform can be expected to be more efficient in reducing insecurity. In that reform, international law secures the group's NLP-satisfaction more directly, by protecting their occupancy rights while leaving the encompassing state's jurisdictional authority (otherwise) in place. The alternative way of reducing insecurity is more efficient due to the relatively lower expected cost of enforcing that legal reform in a world where most states fiercely oppose secessionist-rights for minority groups (ibid, pp. 188-190). In contrast, there are several cases where international bodies successfully monitor and protect occupancy rights for such groups (cf. e.g. cases brought to the Inter-American Human Rights Bodies). ${ }^{9}$

Anna Stilz has attempted to plug the gap in another way: by bolstering the NLPjustification with a Kantian argument. Stilz starts by justifying occupancy rights based on NLPs $(2013 ; 2011$, p. 582-7). She then attempts to justify jurisdictional rights by claiming that rightful occupants on a territory have a general Kantian duty to associate politically with others (in the geographical vicinity) in order to bring about a state with the capacity to establish just relations between persons (2011, p. 578-82). Any well-functioning state which 
exists on the territory where those persons enjoy occupancy rights thereby becomes the legitimate wielder of jurisdictional rights on that territory. ${ }^{10}$

Stilz's conjunction of the life plans-consideration and the Kantian duty has been criticised for being an 'external' ad hoc-move (Ypi 2013, pp. 169-170). This objection is also pressed by Simmons, who further claims that the said conjunction, apart from being ad hoc, threatens to turn Stilz's theory into an 'unstable' hybrid view: its pluralism lacks 'a unifying overall motivation', and thereby 'simply [becomes] a convenient conjunction of elements deriving from views that are essentially in tension with one another' (forthcoming, p. 23).

For reasons of space, I cannot assess the plausibility of these three attempts to close the gap any further here. At any rate, regardless of whether the attempts succeed on their own terms, they are ad hoc. They all need to supplement the life plans-consideration with further normative hypotheses. In contrast, the PLP-account retains the simplicity of a purely life plans-based justification of jurisdictional rights. That is arguably a virtue. Moreover, such simplicity ${ }^{11}$ enables my account to avoid the kind of 'unstable hybrid'-critique pressed by Simmons against Stilz.

Let us now turn to develop this novel justification of jurisdictional rights.

\section{A New Forward-Looking Justification: Political Life Plans}

For present purposes, I assume that, during their lives, people typically develop all sorts of NLPs (as envisaged in the theories of Stilz and Miller). However, as I shall now suggest, a person may also develop a

Political life plan (PLP): to exercise her democratic autonomy as a citizen of the particular (territorial) polity under which she (or her group) $)^{12}$ has lived, or is living. 
The PLP, as I understand it, revolves around two kinds of particular external objects. The first refers to the behaviour of a specific group: the plan involves being able to take part in a particular democratic collective's wielding of jurisdictional authority. The other component is territorial: the PLP also revolves around the specific territorial state through which the particular collective currently wields (or has wielded) jurisdictional authority. Because it revolves around particular external objects, a person's PLP is interfered with whenever those specific objects are made unavailable to her. As I explained above when discussing NLPs, such interference remains even if she is provided with generically similar substitute objects.

What, more specifically, does it mean to have a PLP? How do facts about particular citizenries and particular territorial polities enter into my plans? Let us start with the PLP's behavioural component. How do people plan to partake in their group's democratic behaviour? As the PLP is defined, it allows for significant variation in people's planned mode of participation. Variety among citizens in how they exercise their democratic autonomy: (i) is necessary to realise social phenomena of the relevant kind; (ii) normally exists beyond that which is necessary, and; (iii) may be consistent with their nonetheless sharing the same PLP.

Consider first (i). For many complex social phenomena, the members who partake in them must fill a diverse set of roles the exercises of which combine to realise the phenomena. A group's democratic self-rule is such a phenomenon. In order for a group to carry out the processes of public opinion formation, collective decision-making, and policy implementation, a significant degree of role-differentiation is required. This is especially clear in large-scale representative democracies, where some citizens must be professional politicians, some public servants, and so on. It is hard to deny this. Because citizens have differing roles in the collective democratic process, there must be variety among them in how they plan to exercise their democratic autonomy. People's necessarily diverse plans of 
participation vary in their directness and frequency. To grasp what these continuous variables refer to, consider some examples. Citizen A is content with partaking in her group's democratic activities by periodically casting her vote (say, in national, as opposed to local or regional, elections). Citizen $\mathrm{B}$, on the other hand, votes on all possible occasions. B also decides to join a political party, becomes involved in day-to-day development of policy proposals, and even gets elected to office. A's involvement is relatively indirect (she elects someone to govern on her behalf) and infrequent (she votes each fourth year), whereas B's is more direct (she governs) and frequent (with year-round activities).

Apart from the plan-variation that follows from the necessary role-differentiation found in collective democratic behaviour, it is natural to expect further variation within the role-types. Like A, citizen $\mathrm{C}$ is not a professional politician. But $\mathrm{C}$ casts her vote more frequently than A. C also partakes actively in public opinion formation by writing and responding to chronicles, whereas $\mathrm{A}$ is content with reading the newspapers and occasionally debating with friends and family. The point is that there is room for very significant variation among citizens within the role-types they occupy. What it means to partake in a particular group's democratic self-rule may in principle be cashed out differently for each individual citizen. Moreover, significant variation is, I believe, to be expected in real-world cases. The truth of (ii) seems obvious.

What I have said about the necessity (and the expected prevalence) of (further) planvariation throws light upon what it might mean for people to have a PLP. But none of that matters much if (iii) is false. The reason is this. For the PLP-account to justify collective jurisdictional rights it is crucial that the same PLP is shared among a significant number of citizens. (I explain why in a later section.) But if (i) and (ii) are correct, as I claim they are, does not this indicate that citizens typically have different PLPs? That supposition is wrong. We can distinguish between sublevel and abstract plans. Sublevel plan-variation can be found 
within the same abstract plan. Although citizens A and B plan to exercise their democratic autonomy with different degrees of directness and frequency (at the sublevel), they may share the (abstract) plan to carry on with those diverse activities as a member of the same particular democratic collective. B's plan to sustain her daily democratic activities, as an elected representative of the particular citizenry whose trust she currently enjoys, is an expression of that abstract PLP. And when A, who follows public debate and casts her vote in national election-years, is adamant about her preference for doing so within the particular citizenry where she is currently a member, she endorses the same PLP.

So, the PLP's behavioural component is abstractly defined. As long as it matters to people that their particular citizenry - as it is - is left alone to conduct its democratic behaviour, they share that plan-component. This holds regardless of how they plan to individually partake in that behaviour sublevel-wise. The exact composition of a particular citizenry is not cut in stone of course. Continuous changes in cast are inevitable. As some members die, some come of age. As some immigrate, some emigrate. When I say that a citizenry remains as it is I mean that no modification to it is forcefully imposed by third parties (such as Big).

If we focus solely on its behavioural component, the PLP is not violated when people are relocated to different lands: a person's plan to partake in a particular citizenry's democratic behaviour can typically be sustained without their controlling any specific territory. Suppose the Icelanders were forcefully moved to Greenland but were allowed to reestablish an Icelandic state there. They might then sustain the behavioural component of their PLPs without loss.

The behavioural component is important. But the PLP, as I see it, also has a territorial component. How does this component enter into people's plans? When persons have developed the PLP's territorial component they have organised their lives around their being 
(or becoming) citizens of their particular state as it is (or was). This includes that state's physical configuration - the way it is (or was) erected upon, and integrated in, a certain geographical space. A state's physical configuration can be divided into two parts. The first part refers to the "tools" for democratic self-government, so to speak. What I have in mind here is the infra-structure, buildings, and spaces with which the citizenry exercises its democratic self-governance. To be more specific, this refers to the public buildings which house the legislative assembly, the judiciary, all the branches of the executive (including the state central administration), and all the way down to the local branches of government. It further includes places to gather for public debate, infra-structure for news-broadcasting and other information flows, as well as the complex network of roads and transport systems that enable police and other public servants to implement and uphold laws.

The other part of the state's physical configuration refers to the "materials" on which the tools are to be wielded. To create her art, a printmaker needs a printing press and a hardened steel burin tool. But she also needs copper plates on which to engrave the shapes she desires, and paper sheets on which to print them. Something similar can be said about a state's wielding of jurisdictional authority. The subject of this paper is territorially-defined jurisdictional rights. States who exercise such rights need a territory - a geographical area on which to "engrave" and "print" its jurisdictional authority. The second part of a state's physical configuration extends, then, as I see it, to all the surface areas on which it exercises its jurisdictional authority, as well as to any habitable vertically located sub-surface areas. ${ }^{13}$

To the extent that the objects which go into these two parts of the state's physical configuration are immovable, the PLP's territorial component makes it into a category of located life plans.

A polity's physical configuration is arguably an important part of what makes a specific state into what it is. The PLP's territorial component makes it impossible to relocate a 
state to a (wholly) different geographical area without that state's ceasing to exist in a way which upsets the PLPs of its citizens. Imagine that the Norwegians are forced to leave Norway and create a new state, Norway 2.0 , on a totally different territory but where the conditions necessary for operating a generically similar state are made available to them. All the above-mentioned "tools" - buildings, spaces, infra-structure - are provided, and the Norwegians can immediately start to wield them upon the new "material". Let us assume away transitional costs, as well as the existence of NLPs (which would be interfered with by the relocation). If the Norwegians have developed PLPs, those plans are nonetheless violated in this scenario. The Norwegians would still rule themselves, thus satisfying their PLP's behavioural component. But their exercise of jurisdictional authority would now have to be done through a different territorial state. The "tools" and the "material" which physically constitute that state would be new to them. Even if we assume that Norway 2.0 is generically similar to Norway, it remains true that the Norwegians' plans do not (yet) revolve around that polity. Norway 2.0 just is a different territorial state - one which currently plays no role in their lives.

Let us end this section by focusing in on the crucial issue. Does the PLP-justification solve the gap problem? Does it ground annexation-resistant jurisdictional rights? As seen, a benevolent annexor could rebut any $N L P$-based objection. Although NLPs constrained the policies that the annexor could impose, they did not rule out the annexation itself. That showed the gap in the NLP-argument (qua justification of annexation-resistant jurisdictional rights). However, if Small's citizens have developed PLPs, Big's annexation is forbidden. No unilateral annexation is possible without upsetting such plans. My new PLP-justification thus closes the gap. Moreover, it does so without helping itself to 'external' ad hoc-hypotheses thereby outperforming its NLP-based rivals. 


\section{On the Moral Weight of Life Plans}

My focus has thus far been to explain how plans of a certain (political) content-category might succeed in grounding jurisdictional rights where other (non-political) categories fail. When doing so I have assumed that the interest in plan-satisfaction - the moral consideration at the heart of any life plans-approach - is weighty, regardless of the content of the plans. This assumption, however, is too sweeping. Consider a counter-example. Imagine that white people in the US plan to live in racially uniform neighbourhoods and to be governed by white people. Is their interest in carrying out their racist life plans (RLPs) morally weighty? Our intuitions, I take it, say firmly no. The racists' interest in sustaining their RLPs is no ground for duties of non-interference. ${ }^{14}$ Even though RLPs are clearly deficient, I expect that PLPs do not intuitively lack moral weight. However, we should be able to give a theoretical underpinning to these differing intuitions. How can we explain the moral weight of PLPs without also ascribing weight to RLPs? A plausible answer, I believe, is found within liberal morality.

Following Will Kymlicka's helpful description, liberalism regards each person as having an 'essential interest [...] in leading a life that is good, in having those things that a good life contains' (1989, p. 10). This interest explains why people should have certain basic liberties. We should have the freedom and ability to revise our current conceptions of the good life, because 'we recognize that we may be mistaken about the worth and value of what we are currently doing' (ibid.). However, the interest in leading a good life also requires the freedom to pursue one's currently endorsed projects, because 'no life goes better by being led from the outside according to values the person doesn't endorse. My life only goes better if I'm leading it from the inside, according to my beliefs about value' (ibid, p. 12).

So, the claim made by any life plans-justification - that people have a weighty interest in being left free to carry out their endorsed plans - sits well with the liberal commitment to 
basic individual liberties. How can we pair up that commitment with the intuition that RLPs have no moral weight?

I believe several plausible explanations might be submitted here. But for reasons of space, I will only consider one: the explanation developed from what Ronald Dworkin has argued is the foundation of liberalism. In Dworkin's view, people have a right to basic liberties, including the freedom to pursue one's endorsed projects, because they need such liberties in order to ensure that they are treated as moral equals - as persons owed equal concern and respect (Dworkin 1977, pp. 272-8). Such treatment is owed as a fundamental natural right which people possess 'not by virtue of birth or characteristic or merit or excellence, but simply as human beings with the capacity to make plans and give justice' (ibid, p. 182). Being fundamental, people's exercise of their basic liberties is justified only when consistent with that right (ibid, pp. 273-4).

Dworkin underlines that the right to moral equality is 'highly abstract' (ibid, p. 180). However, on any plausible conception of what it means to treat people as moral equals, such treatment cannot allow for racial oppression. This explains why RLPs lack moral weight. Their pursuit violates moral equality. Because moral equality is what fundamentally justifies non-interference with one's pursuits, any pursuit the content of which violates such equality has no claim to non-interference. As Rawls puts it, conceptions of the good which require 'the repression or degradation of certain persons on, say, racial [...] grounds' are not 'admissible' (1999, p. 462); claims to pursue such conceptions 'have no weight at all' (ibid, p. 386). This view is echoed by Stilz, who underlines that people only have weighty interests in pursuing life plans which are 'morally reasonable', thereby excluding, for example, 'a Nazi's commitment to the goal of exterminating the Jews' (2013, p. 335, n. 17).

So, RLPs are necessarily inadmissible. They cannot satisfy moral equality. They are thus a special case; they are exceptions to the liberal view that life plans generally matter. 
PLPs, on the other hand, will be admissible. As PLPs are defined, their realisation does not embody contempt for persons based upon their race. There is nothing in them which necessarily faults the moral equality-principle. Moreover, what I take to be a necessary aspect of what it means to treat people as moral equals - granting universal suffrage - is built into the PLP-justification. ${ }^{15}$ By definition, PLPs revolve around democratic states; they cannot be used to confer jurisdictional authority upon non-democracies. Non-democratic plans are simply not PLPs. Whatever they are, plans to sustain non-democratic states fail to treat people as moral equals and will therefore lack the requisite moral weight.

As I understand it, then, the PLP-justification of jurisdictional rights is a natural derivation from the liberal commitment to basic individual liberties. That liberal commitment accords PLPs moral weight based upon the importance of being free to pursue whatever admissible conception of the good. Having clarified this moral foundation for the PLPapproach, it is now pertinent to address another issue which has thus far been assumed: that individual interests in sustaining a (shared) PLP can ground a collective right.

\section{Justifying Collective Rights from Individual Interests}

My PLP-justification follows Joseph Raz's conception of collective rights, according to which

a collective right exists when the following three conditions are met. First, it exists because an aspect of the interest of human beings justifies holding some person(s) to be subject to a duty. Second, the interests in question are the interests of individuals as members of a group in a public good and the right is a right to that public good because it serves their interest as members of the group. Thirdly, the interest of no single member of that group in that public good is sufficient by itself to justify holding another person to be subject to a duty (1986, p. 208). 
Raz uses this conception of collective rights to explain how a single person's interest (say, the late Yasser Arafat's) in the collective good of national self-determination (for the Palestinians) is insufficient to ground a right to such self-determination. Because satisfaction of the right to self-determination imposes 'far-reaching demands on the life of whole communities' Arafat's interest alone is insufficient to justify imposing such duties (ibid, p. 207). Arafat might have a weighty interest in realising Palestinian self-determination, but no right that this will happen. However, Raz writes, if we add to Arafat's interest the similar interests of a large number of Palestinians, their 'cumulative interests' are sufficiently weighty to ground a collective right to Palestinian self-determination (ibid, p. 209). The PLP-account takes the same view. It justifies collective jurisdictional rights for citizens based upon the aggregated weight of the interest - held by them severally - in realising their shared (abstract) PLP. ${ }^{16}$

We can now appreciate another crucial contrast between my life plans-justification of jurisdictional rights and the one favoured by Stilz. Recall that located NLPs typically revolve around partaking in shared activities. On Stilz's NLP-justification of occupancy rights, those NLPs confer such rights upon individuals, not collectives (2013, pp. 350-1). As Stilz defines it, an individual's occupancy right includes 'a claim-right against others not to remove one from the area, and not to interfere with one's use of that space in ways that undermine the shared social practices in which one is engaged' (ibid, p. 327-8, my emphasis). This definition seems to imply that my occupancy right entails the right to have others provide me with whatever I need to continue participating in a particular social form. That right would impose burdensome duties on many people. It would deprive (at least some of) those who might wish to withdraw from that shared practice of the liberty to do so. It is therefore unlikely that my interest alone is weighty enough to do the job. For this reason, the occupancy 
right, as Stilz defines it, can hardly be individual. In fairness to Stilz, let me add that her approach is compatible with, and does recognize, some collective occupancy rights as well (2013, pp. 350-1). Moreover, I expect that her approach might be modified to conceive of the relevant rights (to sustain the particular located social practices a person is engaged in) as wholly collective. However, as her theory stands - if I have interpreted it correctly - my “collectivist" life plans-justification arguably enjoys a comparative advantage here. ${ }^{17}$

Does the "collectivist" rights-view I employ imply anything about the number of people who must share a PLP before the collective jurisdictional right exists? It is difficult to say something very specific about this, apart from the fact that, as $\operatorname{Raz}$ (1986, p. 209) underlines, the size of the group does matter. A larger group is required to impose duties the more burdensome that imposition will be for the duty-bearers. Likewise, if the burden shrinks, fewer people are required. It seems to me plausible that the burden-level of respecting claims to jurisdictional authority is typically correlated with territory-size. The number of citizens required for conferring jurisdictional rights will decrease as the size of the territory over which those rights are claimed also decreases, all else equal. This means that the PLPjustification may justify collective jurisdictional rights for citizenries of modern large-scale democratic states, as well as small indigenous tribes. PLPs revolve around institutional arrangements where democratic political relations obtain between citizens. However, there can be various culturally-specific ways of institutionalising such relations. If jurisdictional rights may be ascribed to small citizenries whenever the geographic expansiveness of their territorial claim is duly adjusted, the PLP-justification is in principle widely applicable.

\section{Prevalence-Based Objections}

A worry that has been put to me about the PLP-account concerns the prevalence of PLPs. Do people actually develop such plans in a wide range of cases? Here it is pertinent to underline 
that my restricted aim, as emphasised earlier, is to identify a category of life plans which ground jurisdictional rights for a group if and when those plans are in fact held by its members. The PLP-justification is put forward as a normative theory of jurisdictional rights. A normative theory identifies criteria which must be met before jurisdictional rights are legitimately held. Such criteria of legitimacy might be correct, as Simmons points out, 'even if no actual states fully satisfy them' (2001, p. 315). So, I have no stake in claiming that, when applied, the PLP-justification will in fact ground jurisdictional authority for this or that realworld state. Whether a shared PLP is sufficiently prevalent in the citizenries of those states is an empirical question that cannot be properly addressed within my present scope. Having said that let me end with some brief tentative reflections about this issue.

People might sometimes pay little attention to their PLPs. It seems fair to say that, for most people, their economic plans, for example, will normally take centre-stage in their daily lives. We can distinguish, however, between occurrent and standing plans. A person's plan is occurrent when it is present in her consciousness. The same plan is standing when it is not. A plan can slide back and forth between standing and occurrent status. ${ }^{18}$ This is a natural feature of any kind of life plan. We simply do not think about all our plans all the time. The level of attention a person directs at her PLP will therefore always vary. For some, like citizen A perhaps, the PLP might typically be standing rather than occurrent. However, standing plans are just as real as occurrent ones.

Perhaps the objection could be made stronger. Perhaps many people not merely relegate their PLPs to standing mode quite often, but rather, upon due reflection, do not care much about them at all. Take a recent example from the UK. People seemed more preoccupied with the royal wedding than with the May 2011-referendum on revisions to the electoral system (the so-called Alternative Vote) which happened at the same time. Does this indicate that people typically ascribe little importance to PLPs? I think not. Consider this. 
People may be expected to display little interest in several very important aspects of their lives when those aspects are currently very secure, at least in their fundamentals. The Alternative Vote did not jeopardise the fundamental aspects of the UK democratic order. Regardless of the referendum outcome, British citizens would retain their collective democratic autonomy over British territory. I take it that public attention would be wholly different if that autonomy itself came under fundamental threat. Imagine that a referendum had been called to decide upon the British response to a foreign power's threat of (even benevolent) annexation. In that scenario, I expect that the citizenry's PLPs would become occurrent indeed.

Unsurprisingly, none of this shows that people can be widely expected to have PLPs. They might oppose annexation for other reasons. Perhaps they doubt Big's credibility and worry that the annexation will jeopardise their NLPs after all, despite the assurances. Like Waldron and Stilz did in their NLP-arguments, I cannot do more here than offer my own belief. For what it is worth, then, I do expect that people would oppose annexation even when they are certain not to suffer economic and religious-cultural setbacks, but only lose their political independence (as in Benevolent Annexation). However, to obtain conclusive evidence (either way) we would have to conduct an empirical survey asking people to elaborate on the grounds for their eventual resistance.

This connects to what I above called the "generic, not particular"-objection to the NLP-account. As I said there, that objection applies to any life plans-justification, including my PLP-account. Like Stilz's dairy farmer, who may have developed what Waldron called 'sentimental attachment' to a particular farm, the PLP-account claims that a citizen may become sentimentally attached to a particular polity. If and when she does, she has developed a PLP. Again, in order to determine whether that is the case for any particular citizen, we must ultimately ask her. Until such a study is forthcoming, however, I maintain my tentative 
belief that people typically develop PLPs. ${ }^{19}$ They do not merely strive to be free to carry on with their economic and religious-cultural projects; it is also part of their plans to pursue those projects as members of a particular citizenry, in control of a particular territorial state.

Some critics might accept that people develop the PLP's behavioural component, but question the existence of its territorial one. As I hope is now clear, the validity of that suggestion must ultimately be settled by empirical studies. Its eventual negative impact on my PLP-justification, however, can be theoretically defused here and now. Let us assume, arguendo, that the territorial component is not developed; people's NLPs are their only located plans. Even if that were so, the behavioural component of their PLP would be sufficient, in conjunction with their NLPs, to ground jurisdictional rights over a particular territory. The behavioural component would preclude being placed under someone else's (even benevolent) rule, and the NLPs would preclude being moved somewhere else.

We can now see the asset of what I above called a combined approach. It avoids incorporating an empirical claim which might be controversial. Personally, I continue to find plausible that people typically include a territorial component in their PLPs. Still, I am happy to dispose of that claim for present purposes. It is not needed for establishing that the PLPcategory I defend enables us to justify rights of jurisdiction from a purely life plans-based perspective. $^{20}$

\section{Conclusion}

I have argued that a state's jurisdictional rights can be grounded solely upon its citizens' interest in sustaining a shared PLP. If I am correct, this justification solves the gap problem. It enables us to forbid benevolent annexations, and it does so without relying upon ad hocconsiderations. 
Let me end by re-emphasising the scope of what I claim. When developing my argument, I have assumed that there is something to be said for life plans-based justifications in general. As mentioned at the outset, my aim has not been to fully vindicate the PLPjustification. Such a defence must be pursued elsewhere. However, if my present analysis has been on target, a purely life plans-based justification of jurisdictional rights can overcome the gap problem. That clears at least one significant hurdle on the way to becoming an overall plausible theory of territory.

\section{References}

Angell, K. (2013) 'Do Insecure Property Rights Ground Rights of Jurisdiction? Miller on Territorial Justice', Res Publica, 19(2): 183-192.

Angell, K. (2015) 'Is There a Duty to Modify one's Way of Life? The Case of Territory'. Paper presented at the ECPR General Conference, Montréal, 28 August.

Armstrong, C. (2014) ‘Against “permanent sovereignty” over natural resources', Politics, Philosophy \& Economics, 14(2), 129-151.

Baker, A. (2013) 'Simplicity', The Stanford Encyclopedia of Philosophy, Edward N.

Zalta (ed.), URL=<http://plato.stanford.edu/archives/fall2013/entries/simplicity/>.

Dworkin, R. (1977) Taking Rights Seriously. London: Bloomsbury Academic.

Gans, C. (2008) A Just Zionism: On the Morality of the Jewish State. New York: Oxford University Press.

Goldman, A. (2015) Theory of Human Action. Princeton University Press.

Kymlicka, W. (1989) Liberalism, Community, and Culture. Oxford: Clarendon Press.

Lijphart, A. (1999) Patterns of Democracy: Government Forms and Performance in ThirtySix Countries. New Haven and London: Yale University Press. 
Locke, John. (1988) Two Treatises of Government. ed. P. Laslett. Cambridge: Cambridge University Press.

Meisels, T. (2009) Territorial Rights, 2nd edition. Dordrecht: Springer.

Miller, D. (2007) National Responsibility and Global Justice. Oxford: Oxford University Press.

Miller, D. (2012) ‘Territorial Rights: Concept and Justification', Political Studies, 60(2), 252268.

Miller, D. (2014) 'Debatable lands', International Theory, 6(1), 104-121.

Nine, C. (2008a) 'A Lockean theory of territory’, Political Studies, 56(1), 148-165.

Nine, C. (2008b) 'Superseding Historic Injustice and Territorial Rights', Critical Review of International Social and Political Philosophy, 11(1), 79-87.

Rawls, J. (1999): Collected Papers. Edited by S. Freeman. Cambridge, MA: Harvard University Press.

Raz, J. (1986): The Morality of Freedom. Oxford: Oxford University Press.

Simmons, A.J. (forthcoming) 'Territorial Rights: Justificatory Strategies', Oxford studies in Political Philosophy.

Stilz, A. (2011) 'Nations, States and Territory', Ethics 121(3), 572-601.

Stilz, A. (2013) 'Occupancy Rights and the Wrong of Removal', Philosophy \& Public Affairs, 41(4), 324-356.

Waldron, J. (1992) ‘Superseding Historic Injustice’, Ethics, 103(1), 4-28.

Waldron, J. (2004) 'Settlement, Return, and the Supersession Thesis', Theoretical Inquiries in Law, 5(2), 237-268.

Ypi, L. (2013) 'What's wrong with colonialism', Philosophy \& public affairs, 41(2), 158-191. 
${ }^{1}$ Territorial rights include jurisdictional rights (to make and enforce law on the land), rights to control the land's natural resources, and rights to control movements of persons and goods across its borders (Miller, 2012, p. 253). My focus is jurisdictional rights over particular lands. For a general justification of jurisdictional rights - an explanation for why a system of territorially-defined jurisdictions is desirable -, see Miller (2007, pp. 214-17).

${ }^{2}$ One such issue is whether life plans-based rights are as temporally stable as its proponents expect. Elsewhere I argue that there is a duty to modify one's way of life when this accommodates weighty, yet currently overridden, third-party claims (Angell 2015). However, such a duty is compatible with the present thesis. It can remain true that PLPS may ground jurisdictional rights, although PLP-holders are (occasionally) duty-bound to modify their PLPs over time, thus also modifying the entitlements flowing from their existence.

${ }^{3}$ Stilz includes two additional plan-categories: 'personal relationships' and 'attachment to locality'. The former refers to engagement with 'colleagues, family, and friends'. The latter refers to plans revolving around access to and use of physical sites of religious and spiritual significance to which persons develop 'special identification' (2013, pp. 338-9). Because personal relationships can arguably be incorporated as a sub-category to both economic and religious-cultural plans, and attachment to locality seems containable in the latter, I stick to the more coarse-grained distinction between economic and religious-cultural plans.

${ }^{4}$ I write 'moderately' because the NLP would be even more generic if she cared about farming as such, not dairy farming, etc.

${ }^{5}$ That sentence is deliberately ambiguous between whether such rights are held by individuals or collectives. Stilz claims the first; Miller the latter. Below I argue against Stilz's position, but this issue can be postponed until later.

${ }^{6}$ See Lijphart (1999) for a survey of such arrangements. 
${ }^{7}$ Cara Nine (2008b) has identified a similar gap problem in a basic needs-argument used by Jeremy Waldron to justify jurisdictional rights for colonist-descendants. Nine's helpful critique blazed the trail for my analysis of a gap in the NLP-argument.

${ }^{8}$ I will not give an account of such functions. For present purposes, I assume that states like Australia perform satisfactorily according to any plausible standard.

${ }^{9}$ For remarks which seem to concede at least parts of this critique, see Miller (2014, p. 116). For related criticisms, see Armstrong (2014, pp. 7-8).

${ }^{10}$ To be precise, Stilz must add a third normative hypothesis to ground annexation-resistant jurisdictional rights. This is achieved by invoking a people's 'residual claim [...] to reconstitute legitimate political institutions on their territory when their prior state fails, becomes illegitimate, or is usurped' (2011, p. 591).

${ }^{11}$ This refers to what Baker (2013) calls 'syntactic simplicity': simplicity in 'the number and complexity of hypotheses'.

${ }^{12}$ This parenthesis allows that current members of group G can have PLPs that revolve around the state under which $\mathrm{G}$ lived prior to an unjust usurpation, even when all the members of $\mathrm{G}$ who experienced living under that state have passed away. As I see it, PLPs can be transferred between generations even though the new ones have not experienced controlling the objects/places around which those plans revolve. Here I follow Waldron's claims about transmission of religious-cultural plans (1992, pp. 19-20).

${ }^{13}$ Because sub-surface areas are included, people cannot escape state jurisdiction simply by digging holes and creating subterranean communities.

${ }^{14}$ I owe this example to an anonymous referee.

${ }^{15}$ I do not claim that universal suffrage and rejection of racial oppression exhaust the list of justice-based admissibility-constraints. While several others arguably exist, for reasons of 
space, they cannot be discussed here. However, I expect the PLP-justification to be compatible with various lists of constraints.

${ }^{16}$ Note that similar interests might add different weights to the aggregation. If a person's exercise of democratic autonomy scores high on directness and frequency that activity is a relatively large part of her life. Her sublevel-PLP thus scores high on what I above called comprehensiveness. Comprehensive plans carry larger weight, all else equal. Recall citizens A and B. They share a PLP and the interest in realising it. B's PLP, however, is more comprehensive than A's, and might thus add more weight to the aggregation. This does not mean that A's interest in sustaining her infrequent participation has little weight. A parallel is friendship. Some of our friends we only see sporadically. This need not detract from the great importance in our lives of these meetings.

${ }^{17}$ On the PLP-justification, a single citizen's interest in sustaining the relevant social practice (i.e. her group's political self-determination through a particular territorial state) is not weighty enough to deprive other citizens of the liberty to withdraw from that particular practice. They might not be justified in withdrawing if that would leave the single person without access to any well-functioning state. The question is whether a single citizen's interest can make other citizens duty-bound to sustain a particular political arrangement. ${ }^{18}$ This draws upon Goldman's classic distinction between occurrent and standing wants and beliefs $(2015$, p. 86).

${ }^{19}$ The qualifier 'typically' is crucial. Some persons might regard themselves as citizens of the world and feel attachment to no particular state. Such 'cosmopolites', as Miller (2007, pp. 264-5) puts it, are 'happy to take the best that is on offer wherever this happens to be - the best job, the sunniest climate, and the richest set of leisure activities'. A world largely 
populated by cosmopolites is conceivable. But as Miller points out, it 'would clearly be very different from the world that we know'.

${ }^{20}$ A combined account retains syntactic simplicity. It invokes no external normative hypotheses. The only theoretical extension is in its plan-categories. 